\title{
Effect of Cow Start Calcium Bolus on Metabolic Status and Milk Production in Early Lactation
}

\author{
John Lawlor ${ }^{1, ~ *, ~ A l a n ~ F a h e y ~}{ }^{2}$, Enda Neville ${ }^{2}$, Alice Stack ${ }^{1}$, Finbar Mulligan ${ }^{2}$ \\ ${ }^{1}$ Anchor Life Science Ltd., Co. Cork, Ireland \\ ${ }^{2}$ College of Health and Agricultural Sciences, University College Dublin, Dublin, Ireland
}

Email address:

john.lawlor@marigot.ie (J. Lawlor)

${ }^{*}$ Corresponding author

\section{To cite this article:}

John Lawlor, Alan Fahey, Enda Neville, Alice Stack, Finbar Mulligan. Effect of Cow Start Calcium Bolus on Metabolic Status and Milk Production in Early Lactation. Animal and Veterinary Sciences. Vol. 8, No. 6, 2020, pp. 124-132. doi: 10.11648/j.avs.20200806.12

Received: October 22, 2020; Accepted: November 4, 2020; Published: November 19, 2020

\begin{abstract}
The objective of this study was to quantify the effect of a combined calcium, magnesium and anti-oxidant bolus on early lactation energy status and milk production performance of multiparous dairy cows compared to control, and calcium only bolus intervention. Multiparous $(\mathrm{n}=91)$ cows from a large Irish dairy herd, with a below-average incidence of hypocalcaemia, were enrolled in this study and randomly assigned to either a control ( $\mathrm{CON}, \mathrm{n}=30$ ), a calcium only bolus $(\mathrm{ABC}, \mathrm{n}=30)$ or a combined calcium, magnesium and anti-oxidant (Cow Start calcium) bolus (CSC, $\mathrm{n}=31$ ). CON cows received no bolus and $\mathrm{ABC}$ and $\mathrm{CSC}$ cows received two boluses at 0 - and 12-hours post-partum. Early lactation energy status was studied by recording milk ketone (beta hydroxybutyrate (BHBA)) levels at day 14 and day 28 post-partum, body condition scoring (BCS) of cows at week $0,2,4,6,8$ and 12 post-partum and by weighing cows at week $0,2,4,6$ and 8 post-partum. Cows in the CSC group recorded significantly $(\mathrm{P}<0.05)$ lower milk BHBA levels $(0.43 \mathrm{mg} / \mathrm{dL})$ when compared to CON $(0.98$ $\mathrm{mg} / \mathrm{dL})$ and a trend $(\mathrm{P}<0.10)$ towards lower milk BHBA when compared to ABC $(0.74 \mathrm{mg} / \mathrm{dL})$. The CSC group also showed a trend $(\mathrm{P}<0.07)$ towards reduced body condition loss between calving and nadir $(-0.39 \mathrm{BCS}$ units) when compared to ABC (- 0.53 BCS units). Milk production volumes were significantly increased $(\mathrm{P}<0.05)$ by $1.3 \mathrm{~kg}$ per day from day 5 of lactation until day 90 for the CSC group (30.7kg/day) when compared to CON $(29.4 \mathrm{~kg} /$ day), with a trend $(\mathrm{P}<0.10)$ of $0.8 \mathrm{~kg}$ per day toward higher milk production when compared to the $\mathrm{ABC}$ group (29.9 $\mathrm{kg} / \mathrm{day})$. Body weight change $(\mathrm{kg})$, Milk Fat $\%$ and $\mathrm{kg}$, Milk Protein \% and kg, fat:protein ratio, combined milk components (milk fat and milk protein $\mathrm{kg}$ ), and energy corrected milk were recorded and analysed, with no significant differences observed. Results of this study indicate that cows supplemented with the CSC bolus responded favourably to treatment with regard to improved metabolic status in the critical early lactation post-partum period when compared to control and a calcium only bolus intervention. Results of this study suggest that supplementing dairy cows with a combined calcium, magnesium and antioxidant oral boluses will have beneficial effects for early lactation dairy cows.
\end{abstract}

Keywords: Calcium and Antioxidant Bolus, Early Lactation, Metabolic Status

\section{Introduction}

At parturition the cow experiences significant challenges to calcium homeostasis, brought about by a rapid increase in demand for calcium to support colostrum and milk production. Calcium deficit is further exacerbated as the cow's ability to increase calcium supplies from digestive or skeletal systems can be delayed by $24-48$ hours, leading to an acute deterioration in calcium status. Blood calcium levels below $1.4 \mathrm{mM}(5.5 \mathrm{mg} / \mathrm{dL})$ are associated with clinical hypocalcaemia and a range between $1.4-2.0 \mathrm{mM}(5.5-8.0$ $\mathrm{mg} / \mathrm{dL}$ ) is generally associated with subclinical hypocalcaemia [1]. Numerous studies have shown that it is common for herds to experience clinical hypocalcaemia at rates of $5-7 \%[1,4]$. More recent research findings show herdwide levels of sub-clinical hypocalcaemia of $25 \%$ in primiparous and $47 \%$ in multiparous cows and $16 \%$ in primiparous and $57 \%$ in multiparous cows $[2,5]$.

A key impact of calcium status in the transition cow is its 
effect on dry matter intakes (DMI) and consequently, early lactation energy status. A study by Hansen et al demonstrated an almost linear decrease in feed intake of $25 \%$ when plasma ionised calcium levels were $0.9-0.75 \mathrm{mmol} / \mathrm{L}$. Feed intake approached zero when ionised calcium came close to 0.6 $\mathrm{mmol} / \mathrm{L}$ [6]. Hypocalcaemia also reduces rumen and abomasal motility increasing the risk of displaced abomasum [1]. This reduction in DMI coincides with a dramatic rise in energy demand as the cow enters milk production, which results in an unavoidable period of negative energy balance. In order to address this energy shortfall, the cow must mobilise body fat reserves from adipose tissue. Ketones, such as nonesterified fatty acids (NEFA) and $\beta$-hydroxybuytric acid (BHBA) are byproducts of this process and are routinely monitored as markers for the energy status of the cow, with higher levels of NEFA or BHBA reflecting higher degrees of lipid mobilisation and more critical states of ketosis. Numerous studies have found a correlation between low blood calcium status and elevated levels of circulating ketones (NEFA and BHBA), indicating that compromised calcium status in early lactation may lead to greater energy deficit in the critical transition period [2, 7, 8]. Prolonged periods of negative energy balance lead to elevated rates of body weight or body condition loss which impair immune function and cow fertility. Cows mobilising excessive amounts of body fat are at risk of ketosis or sub-clinical ketosis, with sub-clinical ketosis occurring above a threshold level of 14 $\mathrm{mg} / \mathrm{dL}$ BHBA in blood and $2 \mathrm{mg} / \mathrm{dL}$ in milk $[9,10]$. Prevalence of sub-clinical ketosis is reported at rates of between $10 \%$ and $40 \%$, and associated with production and profitability losses of US\$289 per cow [9, 11-14].

A recent study by Martinez et al demonstrated that concentration and percentages of neutrophils undergoing phagocytosis and oxidative bursts were both reduced in cows with sub-clinical hypocalcaemia, compared to normocalcaemic cows [8]. Cows with sub-clinical hypocalcaemia had 3.24 times greater risk of developing metritis compared to normocalcaemic cows. Furthermore, relative risk of developing metritis decreased by $22 \%$ for every $1 \mathrm{mg} / \mathrm{dL}$ increase in serum $\mathrm{Ca}$ [8]. Given the prevalence and costs associated with hypocalcaemia, much research has been carried out into effective mitigation protocols. Most studies focus on either a pre-partum dietary intervention such as binding calcium in the diet or altering the dietary cation anion difference (DCAD), or some form of calcium supplementation post-partum in an effort to elevate calcium status soon after calving. These include parenteral routes (intra-venous or sub-cutaneous), of calcium administration, and enteral routes (calcium drench or calcium bolus) [15-18]. Most of these strategies have focused on improving calcium status but not many have attended to the energy and immune status of post-partum cows. Indeed, whilst numerous studies have shown a negative correlation between blood calcium levels and NEFA/BHBA status, very little conclusive evidence exists that links the use of calcium supplementation with a subsequent improvement in energy status indicators such as body weight change or body condition score, $[2,8,14,16,17]$. Acknowledging that that post-partum energy and anti-oxidant status are as critical to a successful transition as calcium status is, we propose a proactive approach that addresses more than calcium status alone. In a previous study, Lawlor et al reported a significant decrease in milk BHBA levels in cows supplemented with a combined calcium, magnesium and anti-oxidant bolus (Cow Start Calcium) compared to control, untreated cows [19].

The objective of this trial was to build on these pilot data, and determine if a simple and time critical intervention with a combined calcium, magnesium and anti-oxidant bolus at calving (Cow Start Calcium, Anchor Life Science Ltd., Cork, Ireland.) could improve the metabolic status and productivity of cows in early lactation, when compared to control and a calcium only bolus intervention. It was hypothesised that this intervention would lead to better early lactation outcomes such as 1) better fresh cow energy status, 2) improved milk production and 3) fewer post-partum adverse health events in a dairy herd with effective transition cow management procedures and protocols already in place. In this study, early lactation energy status was assessed by recording milk BHBA levels as well as monitoring body weight and body condition score changes over the first two and three months in lactation, respectively.

\section{Materials and Methods}

\subsection{Study Population}

The study was carried out during the spring, on a large, compact (12 week) seasonal calving herd in Ireland, consisting of 270 cows. The following criteria were used in selecting the herd: participation in the national milk recording program, excellent herd health records including calving events, modern cow sorting and handling facilities and willingness to administer the boluses according to trial protocol. Bolus administration was an existing farm procedure. The study was carried out over a 7-week calving window, study-eligible cows met the following criteria; second lactation or greater with no history of milk fever in previous lactation. Cows were assessed for lameness based on locomotion score (scale 1-5) with cows scoring $>3$ being excluded from the trial. All cows were also individually assessed for body condition score (scale 1-5) with cows scoring $<2.75$ and $>3.50$ excluded from the trial [20]. Multiparous cows were required to have valid on-farm records and have had a full-term pregnancy. All trial eligible cows were then batched and paired by parity into sub-groups. At calving, the cows within these sub-groups were then randomly allocated into one of three groups; control (CON), calcium only bolus (ABC) or Cow Start Calcium (CSC) group.

\subsection{Study Intervention}

189 eligible multiparous cows were due to calve during the study period, of which 91 were enrolled. Three groups were treated as follows; $\mathrm{CON}(\mathrm{n}=30)$ received no oral bolus after calving; $\mathrm{ABC}(\mathrm{n}=30)$ received two calcium boluses (delivering 
$<45 \mathrm{~g} \mathrm{Ca}$ each), as per label recommendations; CSC $(\mathrm{n}=31)$ received 2 combined calcium, magnesium and anti-oxidant (Vit E and Selenium) Cow Start Calcium boluses, as per label recommendations. For both bolus groups, the first bolus was administered within four hours of calving, with an average time of 0.7 hours post-partum. The second bolus was then given to the cow at between 8 and 24 hours after calving, with an average time of 11.2 hours post-partum.

\subsection{Production Data Recording}

All calving, bolus administration and early lactation events were monitored and recorded on farm. As a member of the national milk recording program, on-farm milk samples are taken by an employee of the milk recording service and then sent to an independent accredited laboratory for analysis, to determine milk fat and protein percentage and somatic cell count levels for each cow. The milk component results presented in this study are taken from the first three monthly milk recording sessions in the lactation. Milk volume records were taken from the digital milk meters in the milking parlour (Afi Milk inc.) from each milking (2x daily).

\subsection{Sample/Data Collection and Analysis}

Early lactation energy status in this trial was evaluated by measuring three different parameters - milk BHBA level, body condition score and body weight. Two milk samples (distinct from those collected for the national milk testing program) were taken from each cow at day 14 (+/-3days) and day 28 (+/-3days) of lactation and analysed immediately after milking. Milk was analysed for Beta Hydroxy Butyrate (BHBA) levels (Keto-Test, Elanco Animal Health, Hampshire, UK) as per test instructions. The test reader was blinded as to which group each sample was from, $\mathrm{CON}$, $\mathrm{ABC}$, or CSC. All cows were body condition scored $3-7$ days post-partum and during weeks 2, 4, 6, 8 and 12 of lactation. Body condition scoring, scale of $1-5$ was carried out by two trained personnel who were blinded to treatment group [20]. The score recorded for each cow was agreed upon by both scorers. All cows were weighed on an electronic digital weighing scales at 3-7 days post-partum and during weeks 2, 4, 6 and 8 of lactation. All cows were weighed immediately after morning milking.

\subsection{Statistical Analysis}

Data were obtained from Anchor Life Science and data residuals were checked normality using the UNIVARIATE procedure of SAS (v9.4). All data residuals were found to have a normal distribution with the exception of SCC which was transformed to somatic cell score (SCS) using the transformation SCS $=\log 2(\mathrm{SCC})+3$ [21]. Energy corrected milk (ECM) was calculated as $(0.3246 \times$ kilograms of milk) $+(12.86 \times$ kilograms of fat $)+(7.04$ kilograms of protein $)$ [22]. Calving ease was not considered in the analysis as all cows had a calving ease score of 1 . Cows greater than 4 lactations were grouped into lactation 4 . This left us with three lactation groups; 2, 3 and 4. All cows had an LDA and KET score of 0 across all treatments. Parameters with multiple measures within cow were analysed using repeated measures using the MIXED procedure in SAS (v9.4) the appropriate repeated measures (co)variance structure was selected based on the lowest Bayesian Information Criterion value. Treatment, lactation, day and appropriate interactions were treated as fixed effects and cow was considered as a random effect.

\section{Results}

\subsection{Study Population and Farm Performance}

Overall herd performance for the 2019 spring calving season showed that this herd did not experience higher than average levels of hypocalcaemia and the herd was well below recognised target levels for the major transition cow disorders $[23]^{*}$ (Table 1).

Table 1. 2019 Farm Performance Data.

\begin{tabular}{lllll}
\hline Farm Data for 2019 & & Disease Incidence & Actual & Target* \\
\hline Total Cows Calved & 270 & Clinical Milk Fever & $3.70 \%$ & $<5 \%$ \\
Cows Eligible for Trial & 189 & Retained Placenta & $1.90 \%$ & $<10 \%$ \\
Cows Enrolled in Trial & 91 & Displaced Abomasum & $0.70 \%$ & $<5 \%$ \\
Average Milk Production 2018 (305d proj.) & $6,201 \mathrm{~kg}$ & Ketosis & $0.70 \%$ & $<5 \%$ \\
Calving Interval & 386 & & & \\
\hline
\end{tabular}

\subsection{Early Lactation Energy Status}

\subsubsection{Milk BHBA}

Milk BHBA analysis demonstrated that the CSC group had significantly lower milk BHBA levels compared to CON at day 14 and day $28(\mathrm{P}<0.05)$ and also that the CSC group showed a statistical trend for lower milk BHBA levels at day 14 and day 28 compared to $\mathrm{ABC}(\mathrm{P}<0.10)$ (Figure 1$)$. 


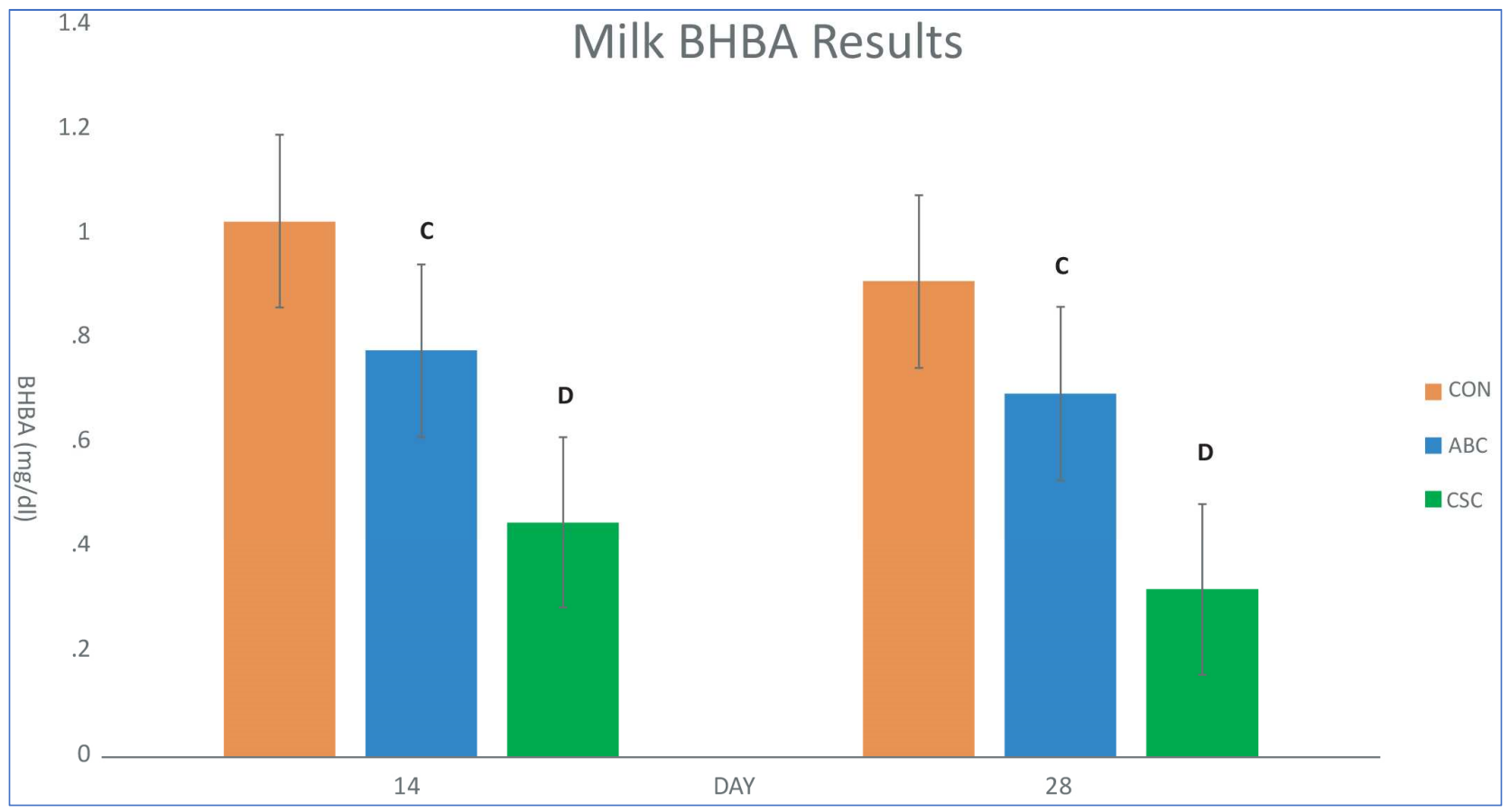

Figure 1. Milk BHBA Results. Least square means ( $($ SEM) for BHBA on day 14 and 28 for CON, ABC and CSC treatments. C, D P $<0.05$.

\subsubsection{Body Condition Score}

Body Condition Scoring results showed that at nadir (week 6$)$ there was a statistical trend $(\mathrm{P}<0.07)$ of less body condition score loss for CSC (-0.39) when compared to ABC (-0.53). There was no difference between CON and CSC groups (Figure 2).

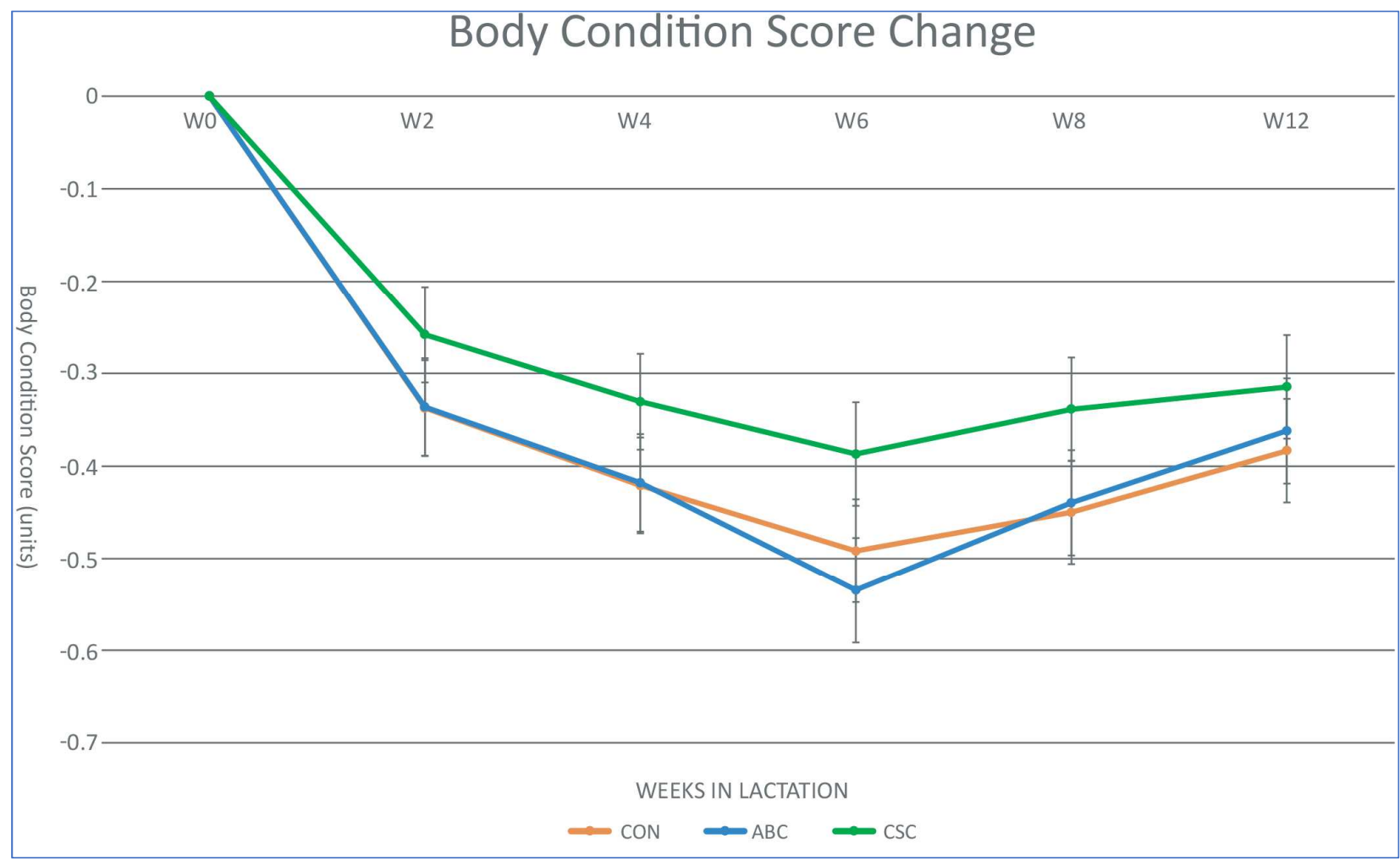

Figure 2. Body Condition Scoring Results. Least square means ( \pm SEM) for body condition score (BCS) from test day 1 to 6 of the experiment for CON, ABC and CSC treatments. There was a statistical trend $(P<0.07)$ of a difference between CSC and CON at W6 (b), there were no statistical differences between CON and CSC (c).

\subsubsection{Body Weight Change}

Body Weight records show that there were no significant differences between treatment groups (Figure 3). 


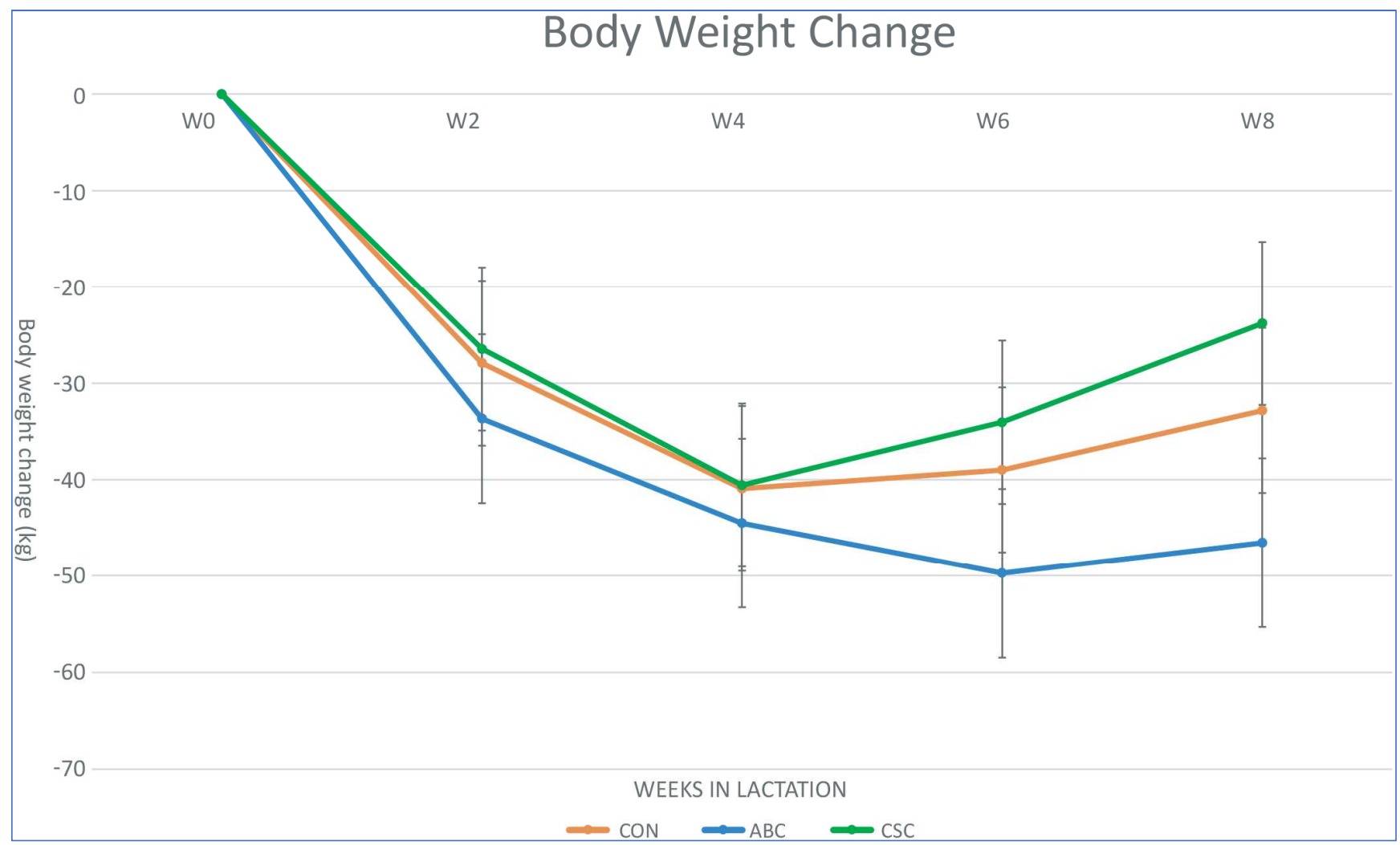

Figure 3. Body Weight Loss in Early Lactation. Least square means ( $(S E M)$ for weight from test day 1 to 5 of the experiment for CON, ABC and CSC treatments.

\subsection{Production Data}

\subsubsection{Milk Volume}

Milk volume production data was collected from each milking for each cow. A significant increase in milk production of $+1.3 \mathrm{~kg} /$ day $(\mathrm{P}<0.05)$ was observed in the CSC $(30.7 \mathrm{~kg} / \mathrm{day})$ compared to CON $(29.4 \mathrm{~kg} / \mathrm{day})$. The results also show a statistical trend of $(\mathrm{P}<0.10)$ towards higher production $+0.8 \mathrm{~kg} /$ day in CSC $(30.7 \mathrm{~kg} / \mathrm{day})$ compared to ABC $(29.9 \mathrm{~kg} / \mathrm{day})$. (Figure 4).

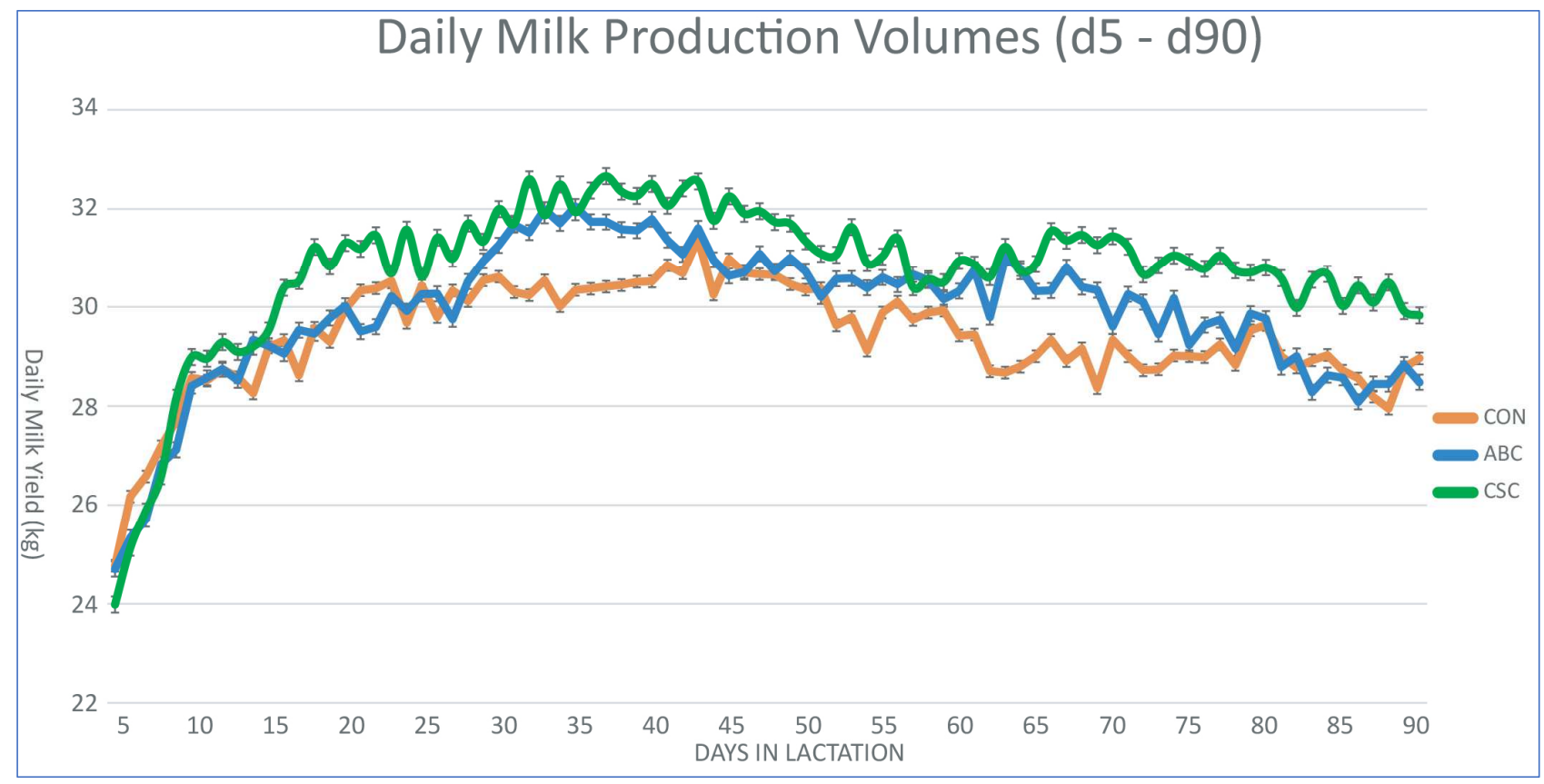

Figure 4. Daily Milk Production. Least square means ( \pm SEM) for daily milk yield from day 5 to 90 of the experiment for CON, ABC and CSC treatments. 


\subsubsection{Milk Recording}

Milk recording results show no significant differences between the three treatment groups in terms of fat and protein percentages, yield and fat:protein ratios. There was also no significant difference with respect to Energy Corrected Milk (ECM) between treatment groups (Table 2).

Table 2. Milk Recording Results.

\begin{tabular}{llllll}
\hline Parameter & CON & ABC & CSC & Pooled SEM & Trt P-value \\
\hline Fat \% & 4.13 & 4.17 & 4.05 & 0.08 & 0.52 \\
Protein \% & 3.29 & 3.27 & 3.28 & 0.04 & 0.88 \\
Fat: Protein & 1.28 & 1.26 & 1.23 & 0.03 & 0.44 \\
Fat Yield (kg) & 1.24 & 1.23 & 1.23 & 0.04 & 0.99 \\
Protein Yield (kg) & 0.99 & 0.96 & 1.00 & 0.03 & 0.32 \\
Fat and Protein Yield (kg) & 2.22 & 2.20 & 2.23 & 0.06 & 0.86 \\
ECM & 32.3 & 32.0 & 32.6 & 1.00 & 0.83 \\
\hline
\end{tabular}

\subsection{Adverse Health Events}

Recording of transition cow disorders (clinical milk fever, retained placenta, uterine infection, displaced abomasum, and ketosis) on the farm demonstrated that although the $\operatorname{CON}(n=9$, or $30 \%)$ and $\mathrm{ABC}(\mathrm{n}=8$, or $27 \%)$ group of cows experienced a higher number of issues compared to the CSC group $(n=3$, or $10 \%)$, the differences were not significant (Figure 5).

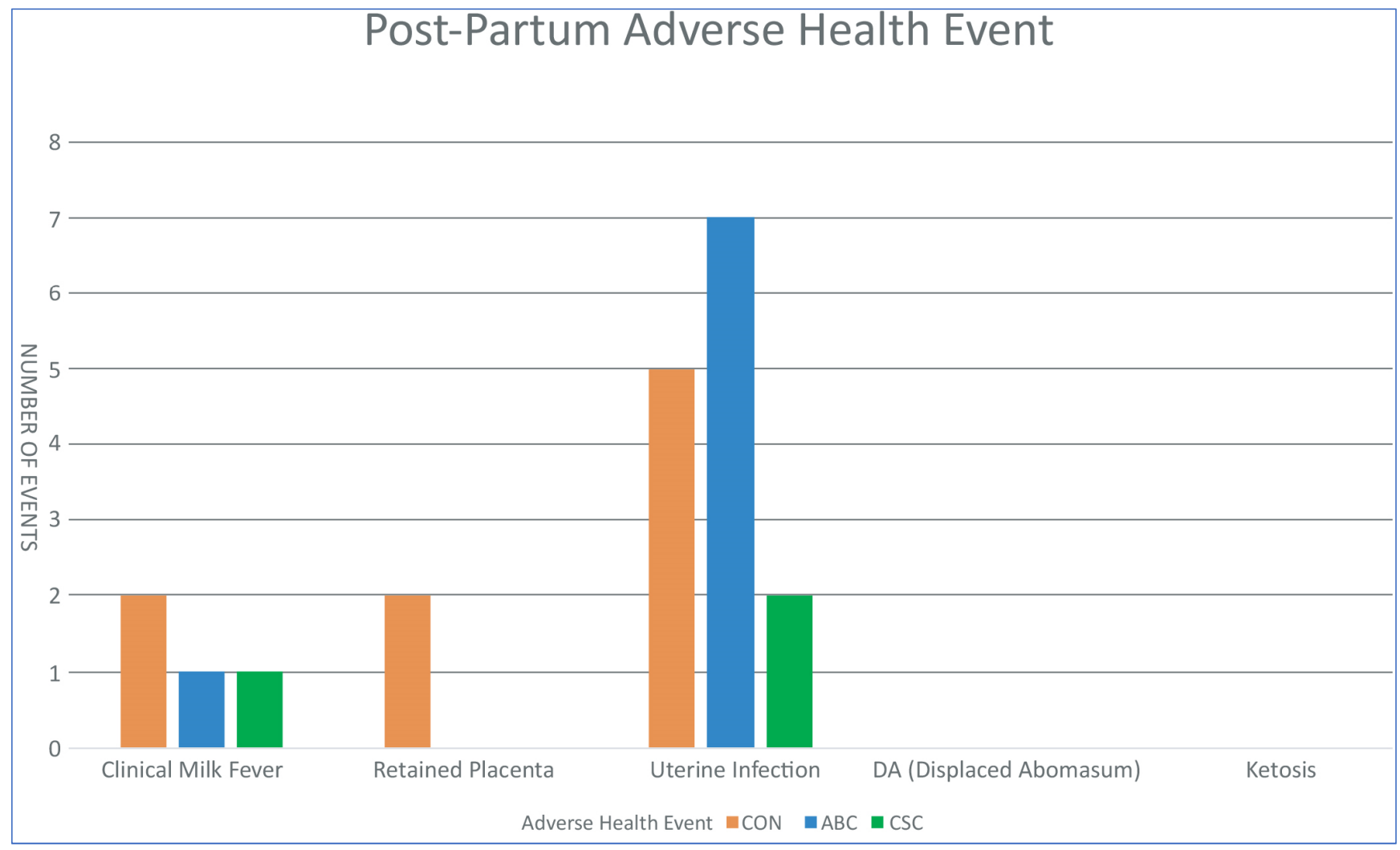

Figure 5. Adverse health events as recorded on farm.

\section{Discussion}

The results of our study demonstrate that cows that received the Cow Start Calcium bolus had improved early lactation metabolic status based on lower milk BHBA and less body condition loss in early lactation, when compared to control and calcium-only bolus treatment groups. The Cow Start Calcium group also recorded a significant improvement in milk production and a numerical reduction in post-partum adverse health events.
The transition period presents the biggest challenge to the dairy cow in her lactation cycle. The abrupt change in her calcium status can lead to reduced dry matter intakes, which in turn lead to a period of negative energy balance and poor metabolic status, as well as excessive body weight and body condition loss $[1,7]$. The combination of impaired calcium and energy status is known to suppress immune function and reduce milk production [1, 24]. This cascade of events is common and costly in dairy herds; clinical hypocalcaemia has a prevalence of $5-7 \%$ and an estimated cost of US $\$ 250$ per case, and sub-clinical ketosis has a prevalence of $10-$ 
$40 \%$, with an estimated cost of US\$289 per case $[9,11,12$, 14, 25].

Cow Start Calcium bolus was formulated in order to address the key nutritional challenges that transition cows face, in particular periparturient hypocalcaemia, by provision of available calcium sources, and sufficient rumen soluble magnesium to enhance calcium uptake [26-28]. By addressing calcium status, negative energy balance is also indirectly treated. Furthermore, the significant antioxidant challenge to the cows' immune status during transition is being addressed. The bolus features a combination of $65 \mathrm{~g}$ of highly available Calcium, $4 \mathrm{~g}$ of Magnesium along with rumen protected (calcified fat matrix) vitamin $\mathrm{E}$ and selenium to aid immune function. Previous studies have demonstrated that both calcium sources used in the Cow Start Calcium bolus; calcium chloride and calcified marine algae, significantly increase blood calcium levels with 30 minutes of administration [29, 30]. The Cow Start Calcium bolus also contains $50 \%$ more calcium than the calcium-only treatment along with $4 \mathrm{~g}$ of Magnesium to enhance calcium uptake [26, 28]. As calcium is required for muscle and nerve function, cows with low blood calcium status are reported to have an impaired ability to stand up, reduced mobility, and reduced dry matter intakes $[1,6]$.

A key finding of a previous research by our group was that cows given the Cow Start Calcium bolus recorded a significant reduction in milk BHBA levels when compared to a control group, indicating a lower level of body fat reserve mobilization [19]. The design of the current study took this finding into account in order to investigate if this milk BHBA finding could a) be replicated and b) whether there was a wider effect on early lactation energy status such as; body condition score and body weight. The milk BHBA result in this study shows a very similar pattern to the previous study with CSC $(0.43 \mathrm{mg} / \mathrm{dL})$ cows having a significant reduction $(\mathrm{P}<0.05)$ compared to $\mathrm{CON}(0.98 \mathrm{mg} / \mathrm{dL})$ and a trend towards reduction in milk BHBA $(\mathrm{P}<0.10)$ compared to $\mathrm{ABC}(0.74 \mathrm{mg} / \mathrm{dL})$. It is reported that BHBA in milk above $2 \mathrm{mg} / \mathrm{dL}$ represents a threshold for sub-clinical ketosis. Therefore, it can be inferred from these results that the CSC group are at lower risk (further from the threshold) of subclinical ketosis when compared to other groups [10].

The CSC group demonstrated a statistical trend $(\mathrm{P}<0.07)$ towards less body condition loss (-0.39 BCS units) between calving and nadir (week 6) when compared to ABC (-0.53). There was no difference between CSC and CON. The CSC and $\mathrm{CON}$ groups both lost $-41 \mathrm{~kg}$ at nadir (week 4) compared to the ABC group which lost $-50 \mathrm{~kg}$ at nadir (week 6). Between nadir and week 8 the CSC group had recovered more body weight $(17 \mathrm{~kg})$ compared to CON $(8 \mathrm{~kg})$ and $\mathrm{ABC}$ ( $3 \mathrm{~kg})$. These data confirm that cows given the Cow Start Calcium bolus experience improved early lactation energy status, and they also provide some detail on how the cows are partitioning the extra energy available to them by means of quicker body condition and body weight recovery.

Milk production levels in the first 90 days in lactation were greatest for the CSC group with a significant increase compared to $\mathrm{CON}(+1.3 \mathrm{~kg} /$ day, $\mathrm{P}<0.05)$ and $\mathrm{ABC}$ $(+0.8 \mathrm{~kg} / \mathrm{d}, \quad \mathrm{P}<0.10)$, without a reduction in milk components. Although not significantly different, the recording of post-partum adverse health events demonstrates that $\mathrm{CON}(30 \%)$ and $\mathrm{ABC}(27 \%)$ groups experienced a higher degree of transition cow disorders compared to the CSC group (10\%).

The increase in milk production in conjunction with an improved energy status would indicate that the CSC group of cows are transitioning better into lactation compared to $\mathrm{CON}$ and $\mathrm{ABC}$. It is possible that this is the result of a higher level of dry matter intake amongst the CSC group, although DMI was not measured in the study. At day 14 of lactation, whilst all three groups of cows have similar levels of milk production, the CSC group has a significantly lower milk BHBA level which would support the theory that cows are benefiting metabolically from higher dry matter intakes. Further studies to specifically investigate dry mater intake levels are required to further investigate this proposed mechanism of action.

After day 14 it was observed that the CSC group increased milk production levels compared to $\mathrm{CON}$ and $\mathrm{ABC}$, and this increase in production continued across the entire first 90 days of lactation (and indeed across the first 180 days of lactation, data not shown). This increase in production is not observed in the $\mathrm{ABC}$ group compared to CON until day 28 in lactation and this advantage over $\mathrm{CON}$ only lasts until day 80 in lactation.

Lactation curve modelling has demonstrated, that the sooner into lactation an animal increases her production, the higher her production will be across the entire lactation [3133]. An earlier increase in milk production may be an indication of a cow that has transitioned better and is in better early lactation metabolic status $[1,17,34]$. If this is the case, we propose that the results of this study support the contention that the CSC group experience a better transition period leading to a better metabolic status at day 14 and day 28 , leading to a significant increase in milk production from day 14 , which in turn leads to increased milk production across the whole lactation. These results support earlier research which shows a link between higher calcium status and lower BHBA status, but also demonstrate a beneficial effect of lower BHBA levels on body condition and production performance in early lactation, [2].

\section{Conclusions}

The results of this trial demonstrate that the prophylactic treatment of a group of freshly calved cows in the second lactation or greater with two oral calcium, magnesium and anti-oxidant boluses had a beneficial effect on early lactation metabolic status of these cows as indicated by significantly lower milk BHBA levels at two postpartum time points, as well as a lower levels of body condition loss. Furthermore, this intervention resulted in a statistically significant increase in milk production levels over the first 90 days in lactation. These findings indicate that the Cow Start Calcium bolus 
intervention established an early, optimal post-partum calcium status which can have longer-lasting benefits during lactation, specifically in terms of energy status, and this benefit was not seen in the control and calcium only interventions in this study.

\section{Disclosures / Conflicts of Interest}

Cow Start Calcium boluses were provided free of charge to the farm by Anchor Life Science. Anchor Life Science covered any cost incurred related to conducting the trial.

\section{Acknowledgements}

The authors would like to acknowledge the cooperation and efforts of the owners and staff at the participating dairy farm for their commitment to conducting the trial. The authors would also like to recognise the effort and support of the veterinary team and staff at Riverview Veterinary Group, Bandon, Co. Cork.

\section{References}

[1] J. P. Goff, "The monitoring, prevention, and treatment of milk fever and subclinical hypocalcemia in dairy cows," Vet. J., vol 176, no. 1, pp. 50-57, 2008, doi: https://doi.org/10.1016/j.tvjl.2007.12.020.

[2] T. A. Reinhardt, J. D. Lippolis, B. J. McCluskey, J. P. Goff, and R. L. Horst, "Prevalence of subclinical hypocalcemia in dairy herds," Vet. J., vol. 188, no. 1, pp. 122-124, 2011, doi: https://doi.org/10.1016/j.tvj1.2010.03.025.

[3] P. J. DeGaris and I. J. Lean, "Milk fever in dairy cows: A review of pathophysiology and control principles," Vet. J., vol 176, no. 1, pp. 58-69, 2008, doi: https://doi.org/10.1016/j.tvj1.2007.12.029.

[4] J. F. Mee, "Prevalence and risk factors for dystocia in dairy cattle: A review," Vet. J., vol. 176, no. 1, pp. 93-101, 2008, doi: https://doi.org/10.1016/j.tvj1.2007.12.032.

[5] Y. Millemann, M. Gillet, P. Kirsch, and Besnier P., "Subclinical hypocalcaemia in French dairy cows," 2016.

[6] S. S. Hansen, P. Nørgaard, C. Pedersen, R. J. Jørgensen, L. S. B. Mellau, and J. D. Enemark, "The effect of subclinical hypocalcaemia induced by Na2EDTA on the feed intake and chewing activity of dairy cows.," Vet. Res. Commun., vol. 27, no. 3, pp. 193-205, Apr. 2003, doi: 10.1023/a:1023340506782

[7] T. Roberts, N. Chapinal, S. J. LeBlanc, D. F. Kelton, J. Dubuc, and T. F. Duffield, "Metabolic parameters in transition cows as indicators for early-lactation culling risk," J. Dairy Sci., vol. 95, no. 6, pp. 3057-3063, Jun. 2012, doi: 10.3168/jds.2011-4937.

[8] N. Martinez et al., "Evaluation of peripartal calcium status, energetic profile, and neutrophil function in dairy cows at low or high risk of developing uterine disease," J. Dairy Sci., vol. 95 , no. 12 , pp. $7158-7172$, Dec. 2012 , doi: $10.3168 /$ jds.20125812 .

[9] G. R. Oetzel, "Monitoring and testing dairy herds for metabolic disease," Vet. Clin. North Am. Food Anim. Pract., vol. 20, no. 3, pp. 651-674, 2004, doi: https://doi.org/10.1016/j.cvfa.2004.06.006.

[10] J. Denis-Robichaud, J. Dubuc, D. Lefebvre, and L. DesCôteaux, "Accuracy of milk ketone bodies from flowinjection analysis for the diagnosis of hyperketonemia in dairy cows," J. Dairy Sci., vol. 97, no. 6, pp. 3364-3370, 2014, doi: https://doi.org/10.3168/jds.2013-6744.

[11] T. Duffield, "Subclinical Ketosis in Lactating Dairy Cattle," Vet. Clin. North Am. Food Anim. Pract., vol. 16, no. 2, pp. 231-253, 2000, doi: https://doi.org/10.1016/S07490720(15)30103-1.

[12] N. Brunner, S. Groeger, J. Canelas Raposo, R. M. Bruckmaier, and J. J. Gross, "Prevalence of subclinical ketosis and production diseases in dairy cows in Central and South America, Africa, Asia, Australia, New Zealand, and Eastern Europe1," Transl. Anim. Sci., vol. 3, no. 1, pp. 84-92, Jan. 2019, doi: $10.1093 /$ tas/txy102.

[13] C. W. R. Compton, S. McDougall, L. Young, and M. A. Bryan, "Prevalence of subclinical ketosis in mainly pasturegrazed dairy cows in New Zealand in early lactation," N. Z. Vet. J., vol. 62, no. 1, pp. 30-37, Jan. 2014, doi: 10.1080/00480169.2013.823829.

[14] J. A. A. McArt, D. V Nydam, and M. W. Overton, "Hyperketonemia in early lactation dairy cattle: A deterministic estimate of component and total cost per case," $J$. Dairy Sci., vol. 98, no. 3, pp. 2043-2054, Mar. 2015, doi: 10.3168/jds.2014-8740.

[15] H. Amanlou, A. P. Akbari, N. E. Farsuni, and N. Silva-del-Río, "Effects of subcutaneous calcium administration at calving on mineral status, health, and production of Holstein cows," $J$. Dairy Sci., vol. 99, no. 11, pp. 9199-9210, 2016, doi: https://doi.org/10.3168/jds.2015-10844.

[16] C. L. Miltenburg, T. F. Duffield, D. Bienzle, E. L. Scholtz, and S. J. LeBlanc, "Randomized clinical trial of a calcium supplement for improvement of health in dairy cows in early lactation," J. Dairy Sci., vol. 99, no. 8, pp. 6550-6562, 2016, doi: https://doi.org/10.3168/jds.2016-10961.

[17] G. R. Oetzel and B. E. Miller, "Effect of oral calcium bolus supplementation on early-lactation health and milk yield in commercial dairy herds," J. Dairy Sci., vol. 95, no. 12, pp. 7051-7065, 2012, doi: https://doi.org/10.3168/jds.2012-5510.

[18] P. Melendez, A. Donovan, C. A. Risco, M. B. Hall, R. Littell, and J. Goff, "Metabolic Responses of Transition Holstein Cows Fed Anionic Salts and Supplemented at Calving with Calcium and Energy1," J. Dairy Sci., vol. 85, no. 5, pp. 10851092, 2002, doi: https://doi.org/10.3168/jds.S00220302(02)74169-6.

[19] J. Lawlor, A. Fahey, E. Neville, A. Stack, and F. Mulligan, "On-farm Safety and Efficacy Trial of Cow Start Calcium Bolus," Anim. Vet. Sci., vol. 7, no. 6, pp. 121-126, 2019, doi: 10.11648/j.avs.20190706.11.

[20] A. J. Edmonson, I. J. Lean, L. D. Weaver, T. Farver, and G. Webster, "A Body Condition Scoring Chart for Holstein Dairy Cows," J. Dairy Sci., vol. 72, no. 1, pp. 68-78, 1989, doi: https://doi.org/10.3168/jds.S0022-0302(89)79081-0.

[21] M. M. Schutz, "Genetic Evaluation of Somatic Cell Scores for United States Dairy Cattle," J. Dairy Sci., vol. 77, no. 7, pp. 2113-2129, 1994, doi: https://doi.org/10.3168/jds.S00220302(94)77154-X. 
[22] H. F. Tyrrell and J. T. Reid, "Prediction of the Energy Value of Cow's Milk1, 2," J. Dairy Sci., vol. 48, no. 9, pp. 1215-1223, 1965, doi: https://doi.org/10.3168/jds.S0022-0302(65)884302.

[23] F. J. Mulligan, L. O’Grady, D. A. Rice, and M. L. Doherty, “A herd health approach to dairy cow nutrition and production diseases of the transition cow," Anim. Reprod. Sci., vol. 96, no. 3, pp. 331-353, 2006, doi: https://doi.org/10.1016/j.anireprosci.2006.08.011.

[24] K. Kimura, T. A. Reinhardt, and J. P. Goff, "Parturition and Hypocalcemia Blunts Calcium Signals in Immune Cells of Dairy Cattle ${ }^{1}, " J$. Dairy Sci., vol. 89, no. 7, pp. 2588-2595, Jul. 2006, doi: 10.3168/jds.S0022-0302(06)72335-9.

[25] D. Liang, L. M. Arnold, C. J. Stowe, R. J. Harmon, and J. M. Bewley, "Estimating US dairy clinical disease costs with a stochastic simulation model," J. Dairy Sci., vol. 100, no. 2, pp. 1472-1486, 2017, doi: https://doi.org/10.3168/jds.201611565 .

[26] R. K. RUDE, S. B. OLDHAM, C. F. SHARP Jr., and F. R. SINGER, "Parathyroid Hormone Secretion in Magnesium Deficiency*," J. Clin. Endocrinol. Metab., vol. 47, no. 4, pp. 800-806, Oct. 1978, doi: 10.1210/jcem-47-4-800.

[27] E. T. Littledike, J. A. Stuedemann, S. R. Wilkinson, and R. L. Horst, "Grass Tetany Syndrome," in Proc. John Lee Pratt Int. Symp. Role Magnes. Anim. Nutr, Virginia Polytechnic Institute and State University, 1983, p. 173.
[28] J. T. Schonewille, "Magnesium in dairy cow nutrition: an overview," Plant Soil, vol. 368, no. 1, pp. 167-178, 2013, doi: 10.1007/s11104-013-1665-5.

[29] J. P. Goff and R. L. Horst, "Oral Administration of Calcium Salts for Treatment of Hypocalcemia in Cattle 1," J. Dairy Sci., vol. 76, no. 1, pp. 101-108, 1993, doi: https://doi.org/10.3168/jds.S0022-0302(93)77328-2.

[30] C. Rossi, "Effects of a supplemental calcified marine algae bolus on blood calcium concentration," 2017.

[31] P. D. P. WOOD, "Algebraic Model of the Lactation Curve in Cattle," Nature, vol. 216, no. 5111, pp. 164-165, Oct. 1967, doi: 10.1038/216164a0.

[32] A. J. Rook, J. France, and M. S. Dhanoa, "On the mathematical description of lactation curves," J. Agric. Sci., vol. 121, no. 1, pp. 97-102, Aug. 1993, doi: $10.1017 /$ S002185960007684X.

[33] D. Sauvant, "Modelling of lactation and nutrition," in Modelling of Livestock Production Systems, J. A. M. Van Arendonk and S. Korver, Eds. Kluwer Academic Publishers, 1988, pp. 149-155.

[34] C. R. Curtis et al., “Association of parturient hypocalcemia with eight periparturient disorders in Holstein cows.," J. Am. Vet. Med. Assoc., vol. 183, no. 5, pp. 559-561, Sep. 1983. 